\title{
Experience with the treatment of bisphosphonate-related osteonecrosis of the jaw
}

\author{
Zuzana Janovska, Radovan Mottl, Radovan Slezak
}

\begin{abstract}
Aim. This article covers the authors' experience with the treatment of bisphosphonate-related osteonecrosis of the jaw in 11 individuals.

Methods. A retrospective study of patients diagnosed and treated for bisphosphonate-related osteonecrosis of the jaw at the Department of Dentistry, University Hospital Hradec Králové during the period January 2006 to October 2012. The treatment protocol consisted of antimicrobial mouth rinses and systemic antibiotic administration according to the stage of the disease. Additional surgical debridement and sequestrectomy in combination with antimicrobial therapy was performed in two cases.

Results. Complete healing was achieved in six patients. In two cases, satisfactory healing was noted. Stage of the disease was lowered and only a small area of asymptomatic necrotic bone of up to five mm in diameter persisted. Two patients developed a stable disease without progression. In one patient, the disease progressed to the third stage with osteonecrosis involving all quadrants of both jaws.

Conclusion. From these data it was concluded that conservative approach in the treatment of bisphosphonate-related osteonecrosis of the jaw led to symptom regression but was not curative. Surgical intervention, however, bears the risk of further progression of the osteonecrosis and must be carefully planned with respect to the patient's general health status and life expectancy. The treatment of bisphosphonate-related osteonecrosis of the jaw is generally difficult. For this reason, prevention plays a predominant role in the management of the disease.
\end{abstract}

Key words: BRONJ, bisphosphonates, osteonecrosis, jaw, treatment

Received: February 18, 2013; Accepted: September 13, 2013; Available online: September 30, 2013 http://dx.doi.org/10.5507/bp.2013.069

Department of Dentistry, Charles University in Prague, Faculty of Medicine and University Hospital Hradec Kralove, Czech Republic Corresponding author: Zuzana Janovska, e-mail:janovani@centrum.cz.

\section{INTRODUCTION}

Bisphophonate-related osteonecrosis of the jaw (BRONJ) is a condition first described by Marx in 2003 (ref. ${ }^{1}$ ). Since then, BRONJ has become a growing epidemic with several thousands of cases reported. Bisphosphonates have been used in human medicine in the treatment of both malignant and non-malignant bone lesions in various diseases, frequently osteoporosis, metastatic bone disease and bone involvement in multiple myeloma. By inhibiting bone resorption, they prevent loss of bone mass, pathologic fractures, pain and hypercalcaemia caused by the underlying disease resulting in significantly positive effect on the quality of life of the affected patients ${ }^{2,3}$. Even though the clinical benefit of bisphosphonate therapy is huge, patients are at risk of developing osteonecrosis as a serious adverse effect. The incidence has been reported to be less than ten percent in various studies ${ }^{4}$. Incidence data for BRONJ vary considerably due to different definitions of the disease. This aside, mild cases of asymptomatic denuded bone very likely remain unidentified ${ }^{5}$. Most incidences of BRONJ have been reported as a result of intravenous administration of high doses of aminobisphosphonates indicated mostly in oncologic patients ${ }^{6}$. The association of BRONJ and non-nitrogen bisphosphonates is very rare ${ }^{7}$. The risk of BRONJ development in patients receiving low doses of bisphosphonates orally mainly for the treatment of postmenopausal osteoporosis is relatively low ${ }^{6,8}$.

According to the American Association of Oral and Maxillofacial Surgeons, the disease is defined as the presence of an area of exposed necrotic bone in the maxillofacial region lasting for more than eight weeks in a patient who was receiving bisphosphonate and had not received radiation therapy to the craniofacial region ${ }^{9}$. This definition does not include so-called, non-exposed' variant, where no denuded necrotic bone is exposed but symptoms and signs such as bone pain, swelling, sinus tract or radiographic abnormality are present. In the pathogenesis defective bone remodelling caused by weakened synergism among the key cells that interact during bone remodeling plays a main role. Disruption of the boneremodelling may be caused by the combination of the underlying disease and the effects of bisphosphonate medication at the lesion site ${ }^{10}$. Minor dentoalveolar surgery such as tooth extraction or chronic trauma of the oral mucosa caused by poorly fitting dentures are common triggering factors of bone exposure. However spontaneous development has also been reported ${ }^{11,12}$. 


\section{MATERIALS AND METHODS}

We performed a retrospective study of all patients diagnosed and treated for bisphosphonate-related osteonecrosis of the jaw at the Department of Dentistry at the University Hospital in Hradec Králové during six years (January 2006 to October 2012). The diagnostic procedure was based on the results of clinical examination. Each patient also underwent radiological examination - panoramic radiography or cone-beam computed tomography to establish the final diagnosis (Fig. 1). The definition and staging system published by the American Association of Oral and Maxillofacial Surgeons was used to determine the stage of the disease ${ }^{9}$ (Table 1). We assigned the patients to the first to the fourth stage of the disease according to the presence or absence of the following symptoms and signs: exposed necrotic bone, pain and evidence of infection, intraoral or extraoral fistula, oro-antral or oro-nasal communication, osteolysis extending to the inferior border of mandible or sinus floor, pathologic fracture (Fig. 2). The treatment protocol included conservative therapy consisting of daily oral antimicrobial rinses (chlorhexidine $0.12 \%$, hexetidine, benzydamin-hydrochlorid) and analgesics. Systemic antibiotic therapy was indicated when signs of infection were present. Antibiotics were administered orally in mild cases of infection. Patients in whom BRONJ manifested with inflammation of deep head and neck spaces were admitted to bed ward for intravenous antibiotic administration. Duration of antibiotic therapy was at least 14 days and always continuing until all signs of infection subsided. Lincosamide antibiotics (clindamycin, lincomycin) and broad-spectrum penicillin antibiotics (amoxicillin) were used. In cases of severe inflammation of deep head and

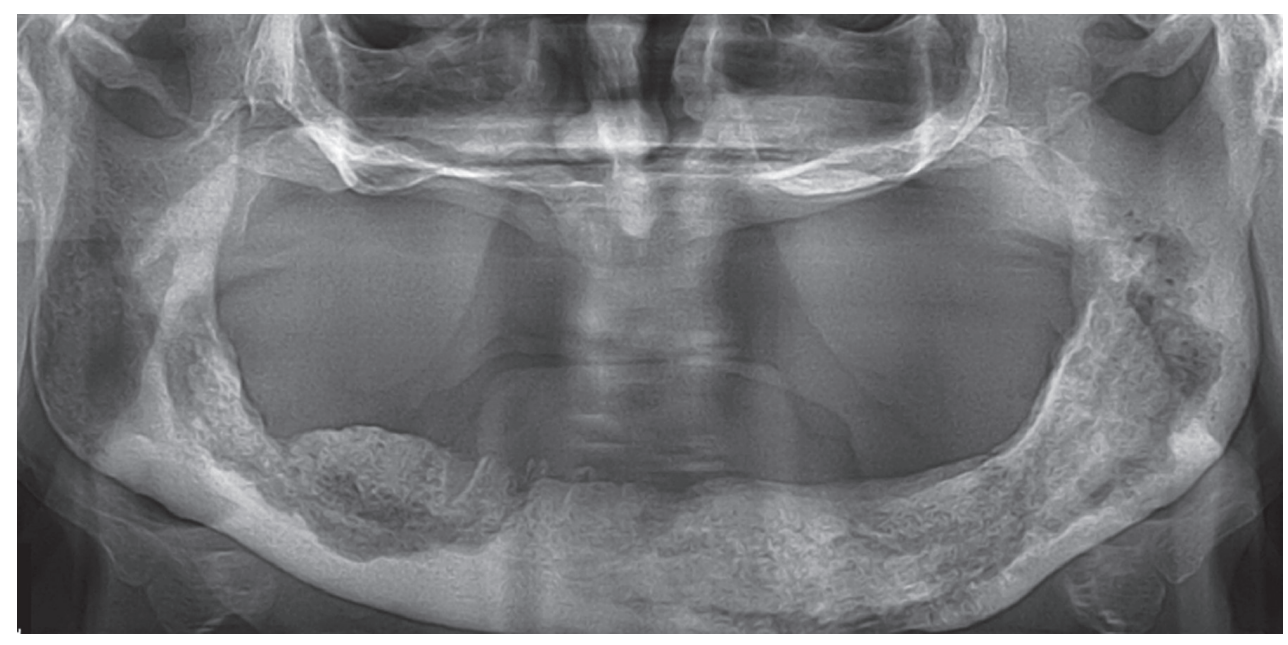

Fig. 1. Orthopantomograph of a patient with significant pathologic bone changes in BRONJ.

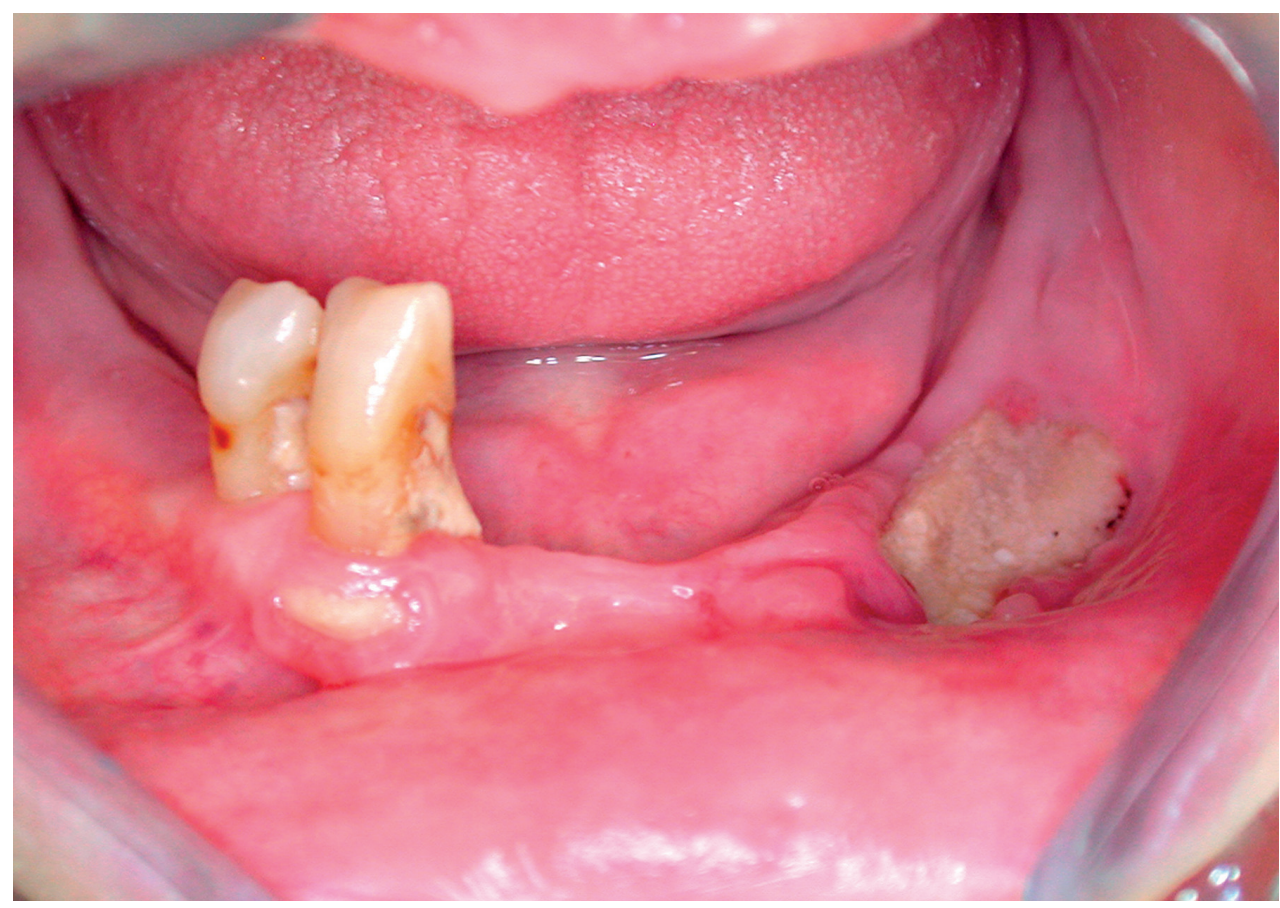

Fig. 2. Exposed necrotic alveolar bone in the oral cavity. 
Table 1. Staging and recommended treatment of BRONJ according to AAOMS.

\begin{tabular}{cll}
\hline Stage & Bone exposure & Recommended treatment \\
\hline 0 & $\begin{array}{l}\text { No bone exposed, but presence of symptoms and signs as jaw bone pain, } \\
\text { bone enlargement, gingival swelling, sinus tracts, radiological abnormalities }\end{array}$ & $\begin{array}{l}\text { Analgesics } \\
\text { Systemic antibiotics }\end{array}$ \\
I & Exposed bone, no symptoms and signs of infection & Antibacterial mouth rinses \\
II & Exposed bone, pain, signs of infection & $\begin{array}{l}\text { Antibacterial mouth rinses } \\
\text { Systemic antibiotics }\end{array}$ \\
& & Analgesics \\
III & $\begin{array}{l}\text { Exposed bone extending beyond the region of alveolar bone, cutaneous } \\
\text { fistula, oro-antral or oro-nasal fistula, pathologic fracture }\end{array}$ & $\begin{array}{l}\text { Antibacterial mouth rinses } \\
\text { Systemic antibiotics }\end{array}$ \\
& & Analgesics \\
& & Surgical therapy (optional)
\end{tabular}

Table 2. Patient data.

\begin{tabular}{ccllll}
\hline Patient & Age/Gender & Diagnosis & Bisphosphonate & Site of necrosis & Triggering cause \\
\hline 1 & $65 / \mathrm{M}$ & Renal cancer & Zolendronate & Maxilla, mandible & Tooth extraction \\
2 & $58 / \mathrm{F}$ & Breast cancer & Zolendronate & Mandible & Tooth extraction \\
3 & $84 / \mathrm{F}$ & Breast cancer & $\begin{array}{l}\text { Zolendronate, } \\
\text { Ibandronate }\end{array}$ & Maxilla, mandible & Tooth extraction \\
& & Clodronate, & Mandible & Denture trauma \\
4 & $66 / \mathrm{M}$ & Multiple myeloma & $\begin{array}{l}\text { Counde } \\
\text { Ibandronate }\end{array}$ & Mandible (bilateral) & Denture trauma \\
5 & $59 / \mathrm{F}$ & Osteoporosis & Ibandronate & Maxilla, mandible & Tooth extraction \\
6 & $85 / \mathrm{F}$ & Osteoporosis & Alendronate & Mandible & Tooth extraction \\
7 & $77 / \mathrm{F}$ & Osteoporosis & Ibandronate & Mandible & Spontaneous \\
8 & $70 / \mathrm{F}$ & Osteoporosis & Ibandronate & Mandible & Spontaneous \\
9 & $60 / \mathrm{F}$ & Osteoporosis & Risendronate & Mandible (bilateral) & Tooth extraction \\
10 & $65 / \mathrm{F}$ & Osteoporosis & Ibandronate & Maxilla & Tooth extraction \\
\hline
\end{tabular}

Table 3. Results of the treatment.

\begin{tabular}{|c|c|c|c|c|}
\hline $\begin{array}{l}\text { Patient } \\
\text { number }\end{array}$ & Type of therapy & Results & $\begin{array}{l}\text { Antibiotics } \\
\text { (Lenght of administration in weeks) }\end{array}$ & $\begin{array}{l}\text { Follow-up } \\
\text { (months) }\end{array}$ \\
\hline 1 & Conservative & Satisfactory healing & Lincosamides (6) & 23 \\
\hline 2 & Surgical - sequestrectomy & Complete healing & $\begin{array}{l}\text { Amoxicillin (5) } \\
\text { Lincosamides (5) }\end{array}$ & 22 \\
\hline 3 & Conservative & Progression & $\begin{array}{l}\text { Amoxicillin(15) } \\
\text { Ciprofloxacin (4) } \\
\text { Lincosamides (41) }\end{array}$ & 82 \\
\hline 4 & Conservative & Stable disease & Lincosamides (5) & 7 \\
\hline 5 & Conservative & Complete healing & $\begin{array}{l}\text { Ciprofloxacin( } 3 \text { ) } \\
\text { Lincosamides ( } 7)\end{array}$ & 30 \\
\hline 6 & Conservative & Stable disease & Lincosamides (13) & 5 \\
\hline 7 & Conservative & Satisfactory healing & Lincosamides (7) & 30 \\
\hline 8 & Conservative & Complete healing & $\begin{array}{l}\text { Amoxicillin (3) } \\
\text { Lincosamides (6) }\end{array}$ & 5 \\
\hline 9 & Conservative & Complete healing & Amoxicillin (3) & 43 \\
\hline 10 & Surgical - debridement & Complete healing & $\begin{array}{l}\text { Amoxicillin (4) } \\
\text { Lincosamides (10) }\end{array}$ & 32 \\
\hline 11 & Conservative & Complete healing & Lincosamides (6) & 3 \\
\hline
\end{tabular}


neck spaces and in patients non-responsive to the previous treatment, ciprofloxacin was used (Table 3). In all cases, egalisation of sharp bony edges was performed whenever necessary to prevent further trauma of the soft tissue. Surgical therapy consisting of sequestrectomy or minor debridement of the necrotic tissue with primary wound closure in combination with systemic antibiotic therapy was performed in two cases.

\section{RESULTS}

From January 2006 to October 2012, we diagnosed 11 patients with BRONJ. The patient age ranged from 58 to 85 years with a mean age 68.5 years. The male-female ratio was 2:9. Postmenopausal osteoporosis was the indication of bisphosphonate administration in seven patients, while four patients received bisphosphonates for one of the following oncologic diseases: prostate cancer (one case), breast cancer (two cases), multiple myeloma (one case). Three oncologic patients were exposed to zolendronate as the most potent bisphosphonate, one patient received oral ibandronate for the treatment of multiple myeloma and the rest were administered oral bisphosphonates, ibandronate (six patients), alendronate (one patient), risendronate (one patient) for the treatment of osteoporosis. The putative cause of BRONJ development was tooth extraction in eight cases, while in two cases it was a spotaneous occurrence and chronic denture trauma was the presumable triggering factor in one case (Table 2). Complete healing defined as the absence of any mucosal breaches and exposed necrotic bone, absence of any signs of inflammation and absence of subjective complaints was achieved in six patients. One of these patients underwent surgical intervention, sequestrectomy with curettage of necrotic bone with primary wound closure supported by systemic antimicrobial therapy and daily oral antimicrobial rinses. Satisfactory healing was achieved in two patients. In these patients a small area of asymptomatic exposed necrotic bone up to five millimeters in diameter persisted. In one oncologic patient, rapid progession with the development of necrotic bone in all quadrants with severe complaints and slow sequstration process was noted. Spontaneous sequestration continued over a period of 5 years. Complete mucosal healing was achieved in the upper jaw but bilateral oroantral communication occurred. In the lower jaw, necrotic bone was persisting. Resective surgery was not indicated in this case due to extensive jaw bone involvement and patient's morbidity. In two cases conservative therapy led to stabilisation of the disease with a minimum or no subjective complaints present (Table 3).

\section{DISCUSSION}

Osteonecrosis as an adverse effect of bisphosponate therapy is a relatively rare complication but may negatively influence patients، oral health. Especially oncologic patients receiving high doses of intravenous bisphopshon- ates have high risk of developing osteonecrosis. Patients receiving lower doses of oral bisphopshonates as in the treatment of postmenopausal osteoporosis are at low risk. Management of the disease is a complicated task since no ideal treatment strategy has been suggested so far. Complete healing is rarely achieved. Most authors agree on conservative treatment strategy which leads to symptom reduction and decrease in the frequency of infectious complications ${ }^{13-15}$. In addition to antimicrobial mouth rinses combined with systemic antibiotic treatment, minor surgical procedures are often performed as a part of the conservative treatment protocol. These include sequestrectomy of mobile bone fragments and egalisation of prominent bony edges. Surgical treatment approach with wide bone resection is controversial since bisphosphonates affect the whole jaw and surgical trauma to the bone could trigger progression of the osteonecrosis. Moreover, visualisation of vital bone margins during the surgery is difficult ${ }^{16}$. For these reasons, the results are not easily predictable. Nevertheless, several reports on resective surgical therapy of BRONJ with positive results have been published so far. These suggest that carefully planned segmental bone resection with pre- and postoperatively administered antiobiotics can result in complete resolution $^{17-19}$. Fluorescence-guided bone resection can aid in the visualisation of vital bone margins during the surgery according to several studies ${ }^{20}$. Yet, careful indication of resective surgery as well as accurate diagnotic procedure and preoperative assessment are necessary. The patient's morbidity and life expectancy should be taken into account when planning surgical intervention. BRONJ seems to be a preventable complication to a certain degree since osteonecrosis is a result of tooth extraction. Less often it may develop spontaneusly or as a result of chronic trauma to the oral mucosa, often caused by ill-fitting dentures $^{21}$. Adverse effects and possible risks should be explained to the patient by the prescribing physician before the therapy onset aand dental preventive measures should be taken ${ }^{22}$. Patients in whom intravenous administration of high doses of bisphosphonates is planned are at higher risk of BRONJ development. Therefore dental examination and treatment of all dental diseases is highly recommended prior to drug administration ${ }^{23,24}$. This requires close cooperation between the patient, the dentist and the physician. Lack of communication could increase the risk of BRONJ development ${ }^{25}$.

Prevention of BRONJ also includes dental care of asymptomatic patients who are already receiving bisphosphonates. The main goal of dental care is to maintain good oral hygiene and to prevent diseases that may lead to the need for invasive osseous procedures, since BRONJ is most frequently a result of dentoalveolar surgery. Elective dentoalveolar surgery does not seem to be contraindicated in patients taking bisphosphonates orally according to AAOMS. In contrast, in high risk patients receiving high doses of intravenous bisphophonates invasive procedures leading to bone injury should be avoided whenever possible. Less invasive treatment methods should be considered instead ${ }^{9}$. In situations when surgical procedures leading to bone injury cannot be avoided, certain precau- 
tions should be taken to minimise the risk of BRONJ development. Teeth should be extracted using the least traumatic technique, preferably one tooth at a time, or by a sextant-by-sextant approach. Wounds should be closed primarily where possible to reduce the time for ingress of oral microorganisms. Many authors suggest the use of perioperative antibiotics and a chlorhexidine mouthwash to reduce the risk of BRONJ development. Antimicrobial prophylaxis should be continued until mucosal seal over the wound is present ${ }^{26}$.

\section{ACKNOWLEDGEMENT}

This work was supported by the research project PRVO UK, No. P37/13/550.

Author contributions: JZ, MR: literature search; JZ: manuscript writing; JZ, SR: study design; JZ: data collection; JZ, MR: data analysis; JZ, MR, SR: data interpretation; JZ: statistical analysis, figures; JZ, MR, SR: final approval.

Conflict of interest statement: The authors state that there are no conflicts of interest regarding the publication of this article.

\section{REFERENCES}

1. Marx RE. Pamidronate (Aredia) and zoledronate (Zometa) induced avascular necrosis of the jaws: a growing epidemic. J Oral Maxillofac Surg 2003;61(10):1238-9.

2. Fleisch H. Bisphosphonates: mechanisms of action. Endocr Rev 2002;19(1):80-100.

3. Rogers MJ, Gordon S, Benford HL, Coxon FP, Luckman SP, Monkkonen J, Frith JC. Cellular and molecular mechanism of action of bisphosphonates. Cancer 2000;88(Suppl. 12):2961-78.

4. Fehm T, Beck V, Banys M, Lipp HP, Hairass M, Reinert S, Solomayer EF, Wallwiener D, Krimmel M. Bisphosphonate-inducedosteonecrosis of the jaw (ONJ): Incidence and riskfactors in patients with brest cancer and gynecologicalmalignancies. Gynecol Oncol 2009;112(3):605-9.

5. Lo JC, O'Ryan FS, Gordon NP, Yang J, Hui RL, Martin D, Hutchinson M, Lathon PV, Sanchez G, Silver P, Chandra M, McCloskey CA, Staffa JA, Willy M, Selby JV, Go AS. Prevalence of osteonecrosis of the jaw in patients with oralbisphosphonateexposure. J Oral Maxillofac Surg 2010;68(2):243-53.

6. Abu-ld MH, Warnke PH, Gottschalk J, Springer I, Wiltfang J, Yahya A, Russo PAJ, Kreusch T. "Bis-phossy jaws" - high and low risk factors for bisphosphonate-induced osteonecrosis of the jaw. J Craniomaxillofac Surg 2008;36(2):95-103.

7. Diel IJ, Fogelman I, Al-Nawas B, Hoffmeister B, Migliorati C, Gligorov J, Väänänen K, Pylkkänen L, Pecherstorfer M, Aapro MS. Pathophysiology, risk factors and management of bisphosphonateassociated osteonecrosis of the jaw: Is there a diverse relationship of amino- and non-aminobisphosphonates? Crit Rev Oncol Hematol 2007;64(3):198-207.

8. Manfredi M, Merigo E, Guidotti R, Meleti M, Vescovi P. Bisphosphonate-related osteonecrosis of the jaws: a case series of 25 patients affected by osteoporosis. Int J Oral Maxillofac Surg 2011;40(3):277-84.

9. Ruggiero SL, Dodson TB, Assael LA, Landesberg R, Marx RE, Mehrotra B. American Association of Oral and Maxillofacial Surgeons position paper on bisphosphonate-related osteonecrosis of the jaws - 2009 update. J Oral Maxillofac Surg 2009;67(Suppl 5):2-12.

10. Subramanian G, Cohen HV, Quek SY. A model for the pathogenesis of bisphosphonate-associated osteonecrosis of the jaw and teripara- tide's potential role in it's resolution. Oral Surg Oral Med Oral Pathol Oral Radiol Endod 2011;112(6):744-53.

11. Bagan JV, Jimenez Y, Murillo J, Hernandez S, Poveda R, Sanchis JM, Diaz JM. Jaw osteonecrosis associated with bisphosphonates: multiple exposed areas and its relationship to teeth extractions. Study of 20 cases. Oral Oncol. 2006;42(3):327-9.

12. Vescovi P, Campisi G, Fusco V, Mergoni G, Manfredi M, Merigo E, Solazzo L, Gabriele M, Gaeta GM, Favia G, Peluso F, Colella G. Surgerytriggered and non surgery-triggered bisphosphonate-related osteonecrosis of the jaws (BRONJ): A retrospective analysis of 567 cases in an Italian multicenter study. Oral Oncol 2011;47(3):191-4.

13. Alons K, Kuijpers SC, De Jong E, Van Merkesteyn JP. Treating low- and medium-potency bisphosphonate-related osteonecrosis of the jaws with a protocol for the treatment of chronic suppurative osteomyelitis: report of 7 cases. Oral Surg Oral Med Oral Pathol Oral Radiol Endod 2009;107(2):1-7.

14. Moretti F, Pelliccioni GA, Montebugnoli L, Marchetti C. A prospective clinical trial for assessing the efficacy of a minimally invasive protocol in patients with bisphosphonate-associated osteonecrosis of the jaws. Oral Surg Oral Med Oral Pathol Oral Radiol Endod 2011;112(6):777-82.

15. Pavlicová A, Vavřičková L, Slezák R, Mottl R. Vlastní zkušenosti s léčbou bisfosfonáty indukovanou osteonekrózou čelistních kostí. LKS 2010;20(5):104-8.

16. Tubiana-Hulin M, Spielmann M, Roux C, Campone M, Zelek L, Gligorov J, Samson J, Lesclous P, Laredo JD, Namer M. Physiopathology and management of osteonecrosis of the jaws related to bisphosphonate therapy for malignant bone lesions. A French expert panel analysis. Crit Rev Oncol Hematol 2009;71(1):1221.

17. Bedogni A, Saia G, Bettini G, Tronchet A, Totola A, Bedogni G, Ferronato G, Nocini PF, Blandamura S. Long-term outcomes of surgical resection of the jaws in cancer patients with bisphosphonaterelated osteonecrosis. Oral Oncol 2011;47(5):420-4.

18. Wilde F, Heufelder M, Winter K, Hendricks J, Frerich B, Schramm A, Hemprich $A$. The role of surgical therapy in the management of intravenous bisphosphonate-related osteonecrosis of the jaw. Oral Surg Oral Med Oral Pathol Oral Radiol Endod 2011;111(2):153-63.

19. Williamson RA. Surgical management of bisphosphonate induced osteonecrosis of the jaws. Int J Oral Maxillofac Surg 2010; 39(3): 2515.

20. Pautke $C$, Bauer F, Otto S, Tischer T, Steiner T, Weitz J, Kreutzer K, Hohlweg-Majert B, Wolff KD, Hafner S, Mast G, Ehrenfeld M, Stürzenbaum SR, Kolk A. Fluorescence-guided bone resection in bisphosphonate-related osteonecrosis of the jaws: first clinical results of a prospective pilot study. J Oral Maxillofac Surg. 2011;69(1):84-91.

21. Kos M, Kuebler JF, Luczak K, Engelke W. Bisphosphonate-related osteonecrosis of the jaws: a review of 34 cases and evaluation of risk. J Craniomaxillofac Surg 2010;38(4):255-9.

22. Bauer JS, Beck N, Kiefer J, Stockmann P, Wichmann M, Eitner S. Awareness and education of patients receiving bisphosphonates. J Craniomaxillofac Surg 2012;40(3):277-82

23. Ripamonti Cl, Maniezzo M, Campa T, Fagnoni E, Brunelli C, Saibene G, Bareggi C, Ascani L, Cislaghi E. Decreased occurrence of osteonecrosis of the jaw after implementation of dental preventive measures in solid tumour patients with bone metastases treated with bisphosphonates. The experience of the National Cancer Institute of Milan. Ann Oncol 2009;20(1):137-45.

24. Schubert M, Klatte I, Linek W, Müller B, Döring K, Eckelt U, Hemprich A, Berger U, Hendricks J. The Saxon Bisphosphonate Register Therapy and prevention of bisphosphonate-related osteonecrosis of the jaws. Oral Oncol 2012;48(4):349-54.

25. Janovská Z. Bisphosphonate-related osteonecrosis of the jaws. A severe side effect of bisphosphonate therapy. Acta Medica (Hradec Králové) 2012;55(3):111-5.

26. Patel V, McLeod NM, Rogers SN, Brennan PA. Bisphosphonate osteonecrosis of the jaw--a literature review of UK policies versus international policies on bisphosphonates, risk factors and prevention. $\mathrm{Br} J$ Oral Maxillofac Surg 2011;49(4):251-7. 